\title{
Heparin-binding epidermal growth factor (HB-EGF) drives EMT in patients with COPD: implications for disease pathogenesis and novel therapies
}

\author{
Mathew Suji Eapen ${ }^{1} \cdot$ Pawan Sharma ${ }^{2,3} \cdot$ Isobel E. Thompson ${ }^{1} \cdot$ Wenying Lu ${ }^{1} \cdot$ Stephen Myers ${ }^{1} \cdot$ \\ Philip M. Hansbro ${ }^{4,5} \cdot$ Sukhwinder Singh Sohal ${ }^{1}$
}

Received: 24 June 2018 / Revised: 7 August 2018 / Accepted: 27 August 2018 / Published online: 19 November 2018

(c) United States \& Canadian Academy of Pathology 2018

\begin{abstract}
Chronic obstructive pulmonary disease (COPD) is a progressive and devastating chronic lung condition that has a significant global burden, both medically and financially. Currently there are no medications that can alter the course of disease. At best, the drugs in clinical practice provide symptomatic relief to suffering patients by alleviating acute exacerbations. Most of current clinical research activities are in late severe disease with lesser attention given to early disease manifestations. There is as yet, a lack of understanding of the underlying mechanisms of disease progression and the molecular switches that are involved in their manifestation. Small airway fibrosis and obliteration are known to cause fixed airflow obstruction in COPD, and the consequential damage to the lung has an early onset. So far, there is little evidence of the mechanisms that underlie this aspect of pathology. However, emerging research confirms that airway epithelial reprogramming or epithelial to mesenchymal transition (EMT) is a key mechanism that drives fibrotic remodelling changes in smokers and patients with COPD. A recent study by Lai et al. further highlights the importance of EMT in smoking-related COPD pathology. The authors identify HB-EGF, an EGFR ligand, as a key driver of EMT and a potential new therapeutic target for the amelioration of EMT and airway remodelling. There are also wider implications in lung cancer prophylaxis, which is another major comorbidity associated with COPD. We consider that improved molecular understanding of the intricate pathways associated with epithelial cell plasticity in smokers and patients with COPD will have major therapeutic implications.
\end{abstract}

\section{Introduction}

Chronic obstructive pulmonary disease (COPD) is a lung disease of major international importance and is caused mainly by cigarette smoking, although indoor and outdoor pollution are also major contributors in poorer nations [1-6]. The disease prevalence according to World Health Organisation (WHO) is estimated to be over 250 million persons, and cause up to 3 million deaths annually (2015), which is $5 \%$ of total worldwide mortality [7]. The disease burden is growing rapidly in developing nations, such as China and India where $90 \%$ of the overall deaths occur, partly due to smoking but also environmental pollution [8]. COPD is characterised primarily as slowly progressive airway narrowing with only partial reversibility at most even after smoking cessation. Vulnerable smokers increasingly develop small airway fibrosis; airway wall thickening that causes narrowing, and subsequent obliteration, accompanied by bronchitis and structural changes that are evident throughout the bronchial tree [9]. Fifty percent of
Sukhwinder Singh Sohal

sssohal@utas.edu.au

1 Respiratory Translational Research Group, Department of Laboratory Medicine, College of Health and Medicine, University of Tasmania, Launceston, TAS 7248, Australia

2 Medical Sciences, University of Technology Sydney, Sydney, NSW 2007, Australia
3 Woolcock Emphysema Centre, Woolcock Institute of Medical Research, University of Sydney, Sydney, NSW 2037, Australia

4 Priority Research Centre for Healthy Lungs, Hunter Medical Research Institute and The University of Newcastle, Newcastle, NSW, Australia

5 Centenary Institute and University of Technology Sydney, Sydney, NSW 2007, Australia 
patients suffer varying degrees of emphysematous lung destruction which further adds to airflow obstruction and symptoms [10]. Nevertheless, airway disease with early small airway destruction is a primary phenomenon with subsequent parenchymal destruction in some patients [9].

\section{Normal and damaged airway mucosa}

In the airways and lungs, the epithelial lining of the mucosa forms the frontline line of defence against outside environmental exposure [11]. It is a mechanical barrier to toxins emanating from smoke and infective microorganisms, through mucus secretion [12] and ciliary clearance [13]. Further, epithelial cells also protect the underlying mucosa by producing several antibacterial, oxidising molecules, proteases and cellular tight junctions make them impregnable to toxin damage [14], as well as innate immune responses to protect against infection [1-3, 15-17]. However, persistent exposure to external insults damages the normal architecture of the epithelium, pathologically indicated by squamous cell metaplasia of the normal pseudostratified columnar tissue, basal cell abnormalities and reprogramming, and goblet cell hyperplasia $[9,18,19]$. The fundamental alterations that occur in epithelial cells is through inducible genomic and transcriptomic reprogramming [20, 21]. This is directly linked to epithelial to mesenchymal transition (EMT), a process of profound epithelial cell plasticity. Cells progressively lose their polarity and adhesiveness, and become migratory by gaining mesenchymal characteristics while progressively losing epithelial-associated markers such as E-cadherin [19, 22-24].

\section{EMT in COPD}

In COPD, there is emerging evidence of EMT being associated with airway remodelling and obliteration, which have been shown in idiopathic pulmonary fibrosis (IPF) and cancer [25-27]. EMT is now increasingly considered as a possible core pathophysiological factor in COPD progression [28]. This is especially evident from our initial observations of increased epithelial expression of mesenchymal markers, such as S100A4 and vimentin in large and small airways of COPD patients compared to non-smokers [29, 30]. Other consequences of EMT in COPD are increased cleft formation in the underlying reticular basement membrane (Rbm) [31, 32]. This is suggestive of matrix metalloproteases (MMPs) activity, especially MMP9, whose epithelial and $\mathrm{Rbm}$ cell expression significantly increases in COPD patients [9, 31, 33]. Further, in vitro evidence showed that cigarette smoke extract (CSE) exposure of normal primary human broncho-epithelial cells (pHBECs) induced EMT activity and increased expression of mesenchymal markers such as $\mathrm{N}$-cadherin and $\alpha$-smooth muscle actin ( $\alpha$ SMA) with concomitant decreases in Ecadherin and $\alpha$-catenin [34]. This may occur via ROS production, increased TGF- $\beta 1$ expression and decreased cAMP levels. Roles for urokinase plasminogen activation receptor (UPAR) in modulating EMT and direct associations between UPAR and vimentin expression in were also suggested [34]. Mitochondrial dysfunction can also lead to EMT in smokers and COPD, hence cancer [35].

Phosphodiesterase-4 (PDE4) inhibitors abrogated EMT events by increasing cAMP levels [36, 37]. Inhibiting TGF- $\beta 1$ with monoclonal antibodies, during in vitro differentiation of pHBECs prevented mesenchymal release of vimentin and fibronectin [38]. Notably, our group reported elevated levels of epidermal growth factor receptor (EGFR) expression, a member of the ErbB (v-erb-b oncogene homologue) family of tyrosine kinase receptors, especially in areas that were positive for EMT markers [31]. We also observed that EGFR was ubiquitous in both large and small airway epithelium of current and ex-smokers with COPD, and their expression was greater than smokers with normal lung function, indicating COPD is associated with exaggerated EGFR expression [29]. EGFR levels in the small airways of COPD patients were associated with decrease in airway functionality.

\section{Potential EMT treatments}

In a "proof of concept" randomised controlled trial, we reported that inhaled corticosteroid fluticasone propionate is effective in reducing mesenchymal expression S100A4, vimentin, EGFR and MM9 expression in COPD patients $[4,27,39-41]$. This is the first clinical study to show the anti-EMT effects of ICS. We also observed effects on vascular remodelling in COPD patients [42], angiogenesis [43] is also major part of EMT when associated with the formation of pro-cancer stroma [22]. In epidemiological studies, it is observed that ICS treatment of COPD patients significantly reduces lung cancer risk but the underlying mechanisms are not clear [44]. It is quite possible that ICS provide protection against lung cancer by ameliorating the EMT process in COPD patients [39, 40]. However, ICS are reserved for more severe forms of COPD and predispose to pneumonia $[45,46]$ by suppressing immunity [1-4, 47]. Consequently, there is a critical need for new drugs, which can be given early in the disease to protect against lung cancer [4, 27, 41]. It is important to note in this context that $70 \%$ of lung cancers occur in early disease 
[48]. EMT certainly seems to be a novel therapeutic target in COPD and potentially lung cancer [39, 40].

\section{EGF:EGFR family as therapeutic target}

The role of EGFR in lung cancer is well documented and mutations in its tyrosine kinase domain are observed in $25 \%$ of non-small cell lung carcinoma (NSCLC) [49]. Largely, these mutations are attributed to short in-frame deletions in exon 19 or as point mutations in exon 21 [50]. These aberrations lead to constitutive activation of the tyrosine kinases, causing unrestricted cellular growth and proliferation [50]. Previous studies have attributed EGFR and its ligand EGF binding as major contributors to squamous cell metaplasia, the outgrowth of epithelial cells most notably in smokers and COPD, and signals for cancer initiation [51, 52]. EGFR is also utilised by virus such as influenza- A virus to cause infection, and infections are an emerging cause for promoting lung cancer [53], again EMT could be central to this [2, 54]. Interestingly, in smokers and COPD patients, both EGFR and mesenchymal markers such as S100A4 and vimentin are highly expressed, but more so in basal epithelial cells compared to the more differentiated ciliated epithelium [29, 55]. This potentially makes basal cells a viable "stem" cell-like population capable of cellular transition and increasing their vulnerability to a cancer phenotype.

Although EGF is considered as the main ligand that induce EGFR activity, other ligands of the EGF superfamily, such as transforming growth factor- $\alpha$ (TGF- $\alpha$ ), heparin-binding EGF-like growth factor (HB-EGF), amphiregulin (AREG), betacellulin (BTC), epiregulin (EREG), and epigen (EPGN) also play crucial roles in EGFR stimulation and regulation [56]. Among these ligands for EGFR, the role of HB-EGF has been particularly found to be important and its negation results in multiple mammalian embryonic development abnormalities including postnatal lethal consequences, such as malformed heart valves, hypertrophic cardiomyocytes, and hypoplastic lungs [57]. HB-EGF is also highly expressed in various forms of cancers, including lung, wherein it is transformed from a benign proHB-EGF to an active HB-EGF motif essentially through ectodomain shedding actions carried out by a disintegrin and metalloproteinase (ADAM) group of proteases [56]. Once cleaved, HB-EGF causes rapid phosphorylation of EGFR that activates intracellular mitogen-activated protein kinase (MAPK) signalling pathways, subsequently increasing cellular propensity to proliferate and invade [50, 57]. Interestingly, the ectodomain shedding of proHB-EGF also induces the transactivation of both extra-cellular and intra-cellular receptors, thus widening the scope of their cellular signalling repertoire, which again could be linked to
EMT progression, as shown in Fig. 1 [58-61]. In epidermal cells such as keratinocytes HB-EGF under physiological conditions plays an important role in re-epithelization in response to injury and is active in skin wound healing by inducing increases in keratinocyte proliferation [62]. In smokers and COPD patients, oxidative stress caused by toxins from cigarette smoke is a crucial factor causing lung epithelial injury, and these alterations in pathological conditions could generate large numbers of EGFR ligand including HB-EGFR.

\section{Role of HB-EGFR in promoting EMT}

The recent study by Lai et al. [63], demonstrated increases in HB-EGF levels in the sputum and lung tissue of smokers and COPD patients compared to non-smoking controls. Moreover, increases in sputum levels and lung tissue expression of HB-EGF were prominent in smokers with or without COPD rather than ex-smokers. This suggest that smoking alone may induce increase in HB-EGF concentrations, while smoking cessation could abrogate this effect, which warrants further studies. Again, of significant patho-physiological consequence was the association of increased HB-EGF sputum levels with increasing severity of the disease (GOLD stage I-IV), further indicating that the potent activation of these pathways may occur in later stages of the disease. However, this needs to be deciphered mechanistically. The authors further examined the role of HB-EGF in changes in airway cellular function and found that it induced EMT in human bronchial epithelial (HBE) cells, which was confirmed by increases in mesenchymal marker expression such as $\mathrm{N}$-cadherin and vimentin and reductions in the epithelial marker E-cadherin. Interestingly, associations were also found between increased levels of sputum HB-EGF and mesenchymal marker expression in the lung tissue. Similarly in previous studies, HB-EGFoverexpressing keratinocytes displayed a characteristic EMT phenotype which included reduced E-cadherin expression, increased vimentin and cellular redistribution of nuclear proteins $\beta$-catenin, SNAIL and ZEB-1 [62]. Further evidence is provided by breast cancer research wherein cells with aberrant expression of EGFR expression undergo EMT-related changes via stimulation of the ligands HB-EGF and cytokines such as TNF $\alpha$ [61]. Increases occur in perinuclear TWIST (an EMT-associated transcription factor) expression as well, via activation of the STAT3 pathway (Fig. 1).

There is emerging evidence that EMT in COPD and other chronic lung diseases is activated by canonical pathways such as TGF- $\beta$, which induce expression of nuclear transcription factors pSMAD2/3 and reduced inhibitory SMAD6/7 expression $[64,65]$. Interestingly, TGF- $\beta$ and 


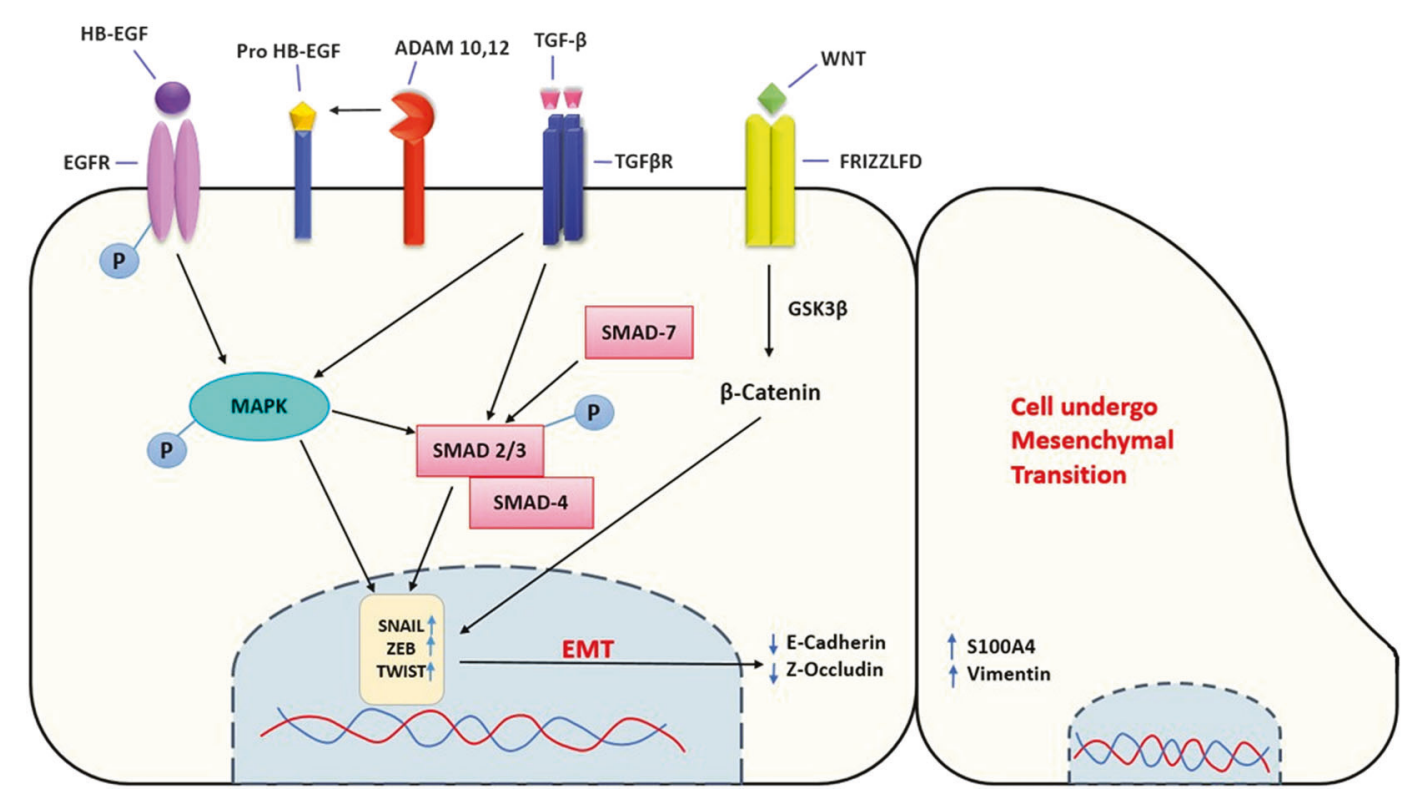

Fig. 1 The potential role of HB-EGF like growth factors in promoting epithelial-mesenchymal transition (EMT)

EGFR pathway transactivation are observed in cancer cells and their synergism induces EMT-related phenotypic changes [61]. TGF- $\beta$ also induces and promotes the increased expression of ligand EGF, EGFR and its associated signalling pathways [66]. Although, TGF $\beta$ triggered pathways are crucial, other canonical pathways, such as Wingless/integrase-1 (Wnt) mediate epithelial changes in COPD pathology [67]. Nicotine, a major component of cigarette smoke was found to promote EMT-related phenotypic changes in bronchial epithelial cells via WNT-3A/ $\beta$-catenin-dependent events [68]. Adding to complexity is the more recent evidence of active non-canonical pathways of Wnt signalling in bronchial epithelial cells from smokers and COPD patients. Wnt5B modulated EMT changes independent of $\beta$-catenin possibly through the induction of TGF- $\beta$ /SMAD3 signalling [69].

Other reports have also suggested cross talk between TGF- $\beta /$ SMADs and Wnt/ $\beta$-catenin pathways in TGF- $\beta$ induced alveolar epithelial cells and these interactions led to increases in $\alpha$ SMA positive myofibroblasts, the final outcome of EMT [70]. Our group previously reported increased expression of $\beta$-catenin in the large airways of both smokers and COPD patients [71]. In the latter there were considerable increases in nuclear to cytoplasmic ratio of $\beta$-catenin suggesting active translocation and possible transcription of genes that are associated with transitional mesenchymal proteins. Further, transcriptional factors such as SNAIL1/2, ZEB1/2 and TWIST, could also be independently activated by either canonical or non-canonical pathways, which again were found to translocate into the epithelial nucleus of COPD patients [71]. Understanding the complex intricacies of HB-EGF/EGFR transactivation in regulating downstream EMT pathways may be an important way forward, and thus, further investigations of their roles in chronic lung disease manifestations are warranted.

\section{Role of the extracellular matrix (ECM)}

The main source of airflow limitation observed in COPD is the pathological changes that affect the airway wall, especially in the small airways, wherein noticeable tissue remodelling and scarring occurs, so that there is fundamental reorganisation of the ECM [10]. These aberrant changes in the ECM have profound effects on the airway wall; the most critical is the gradual obliteration of the small airway lumen. The cell type that is primarily involved in ECM production and deposition are the active fibroblasts called myofibroblasts. These cells are of mesenchymal origin, have a spindle-shaped morphology, and are contractile [72]. The contractible nature of myofibroblasts is associated with the expression of $\alpha \mathrm{SMA}$ myofilaments, which form part of the non-muscle cell population. Interestingly, there have been contrasting data on myofibroblast populations in human bronchi and bronchiolar tissue. Lofdahl et al. [73], showed increases in $\alpha$ SMA positive cells in the lamina propria of the large airways in COPD patients compared to non-smoking controls, although changes in the expression levels were not so distinct in small airways [74]. In contrast, fibroblasts isolated from the distal end of the small airways from COPD patients had increased contractile properties, 
associated with increases in myofibroblasts [75]. Myofibroblast secretes a broad repertoire of ECM proteins that includes fibrous proteins, such as collagen and elastin, and glycoproteins such as fibronectin, tenascin $\mathrm{C}$, and some proteoglycans $[76,77]$. Further, co-localisation of $\alpha$ SMApositive fibroblastic cells along with collagen expression in the small airways in COPD provides essential evidence of their close association and interactions [78]. Although, the presence of myofibroblasts has been confirmed, there has been little direct evidence of their origins, differentiation and regulation. Thus, the current observation of Lai et al. [63], of HB-EGF regulating fibroblastic changes may hold both clinical and therapeutic significance. Their finding of dose dependent increases in collagen I, III and $\alpha$ SMA expression in fibroblasts treated with HB-EGF, provides initial proof-of-concept that this ligand is also involved in fibroblast proliferation and maturation, which is further evident from increases in phosphorylated ERK and p38 [63]. Nevertheless, further independent mechanistic studies are required to elucidate whether these are EGFR driven or are their other more complex interactions at play.

\section{Conclusions}

We consider that there is sufficient clinical evidence to suggest that EMT plays an important role in disease manifestations of COPD, and is thus a new therapeutic target. However, few studies have examined the molecular mechanisms that underlie this process. The study by Lai et al. provides crucial physiological and mechanistic understanding of the role of EGF ligand HB-EGF in regulating EMT and fibrosis, possibly through yet unexplored transactivation pathways. Other studies, including in vivo mouse models that replicate the pathologic features of EMT and fibrosis [79], and potentially exacerbations [47, 80-87], could be valuable in elucidating mechanisms identifying therapeutic targets and test new therapies [88]. Validation using combinations of in vivo and ex vivo human studies [42, 89-93] will provide powerful evidence for their roles and potential targeting in COPD [80,94]. There could be wider implications for other lung diseases, such as idiopathic pulmonary fibrosis (IPF) and lung cancer where EMT activity and fibrosis are prevalent [25, 79, 95]. Further, possible new therapeutic strategies can now be designed that mitigates these interactions, though further research in this area is mandated.

Acknowledgements SSS is supported by Clifford Craig Foundation Launceston and Thoracic Society of Australia and New Zealand (TSANZ) and Boehringer Ingelheim COPD Research Award, PS is supported by Rebecca L. Cooper Medical Research Foundation, Australia and Chancellors Fellowship Programme, University of
Technology Sydney (UTS). PMH is supported by an NHMRC Principal Research Fellowship and a Brawn Fellowship, Faculty of Health, University of Newcastle.

\section{Compliance with ethical standards}

Conflict of interest The authors declare that they have no conflict of interest.

\section{References}

1. Eapen MS, Myers S, Walters EH, Sohal SS. Airway inflammation in chronic obstructive pulmonary disease (COPD): a true paradox. Expert Rev Respir Med. 2017;11:827-39.

2. Eapen MS, Sohal SS. Understanding novel mechanisms of microbial pathogenesis in chronic lung disease: implications for new therapeutic targets. Clin Sci. 2018;132:375-9.

3. Sohal SS. Inhaled corticosteroids and increased microbial load in COPD: potential role of epithelial adhesion molecules. Eur Respir J 2018;51.

4. Sohal SS, Eapen MS, Ward C, Walters EH. Airway inflammation and inhaled corticosteroids in COPD. Eur Respir J 2017;49.

5. Keely S, Talley NJ, Hansbro PM. Pulmonary-intestinal cross-talk in mucosal inflammatory disease. Mucosal Immunol. 2012;5:7-18.

6. Budden KF, Gellatly SL, Wood DL, et al. Emerging pathogenic links between microbiota and the gut-lung axis. Nat Rev Microbiol. 2017;15:55-63.

7. World Health Organisation (WHO). Chronic obstructive pulmonary disease (COPD)-key facts. http://wwwwhoint/news-room/ fact-sheets/detail/chronic-obstructive-pulmonary-disease-(copd); 2016.

8. Lelieveld J, Evans JS, Fnais M, Giannadaki D, Pozzer A. The contribution of outdoor air pollution sources to premature mortality on a global scale. Nature. 2015;525:367.

9. Sohal S, Ward C, Danial W, Wood-Baker R, Walters EH. Recent advances in understanding inflammation and remodeling in the airways in chronic obstructive pulmonary disease. Expert Rev Respir Med. 2013;7:275-88.

10. Eapen MS, Myers S, Walters EH, Sohal SS. Airway inflammation in chronic obstructive pulmonary disease (COPD): a true paradox. Expert Rev Respir Med. 2017;11:827-39.

11. Jolly MK, Ward C, Eapen MS, et al. Epithelial-mesenchymal transition, a spectrum of states: role in lung development, homeostasis, and disease. Dev Dyn 2017;247:346-358.

12. Reid AT, Veerati PC, Gosens R, et al. Persistent induction of goblet cell differentiation in the airways: therapeutic approaches. Pharmacol Ther. 2018;185:155-69.

13. Brune K, Frank J, Schwingshackl A, Finigan J, Sidhaye VK. Pulmonary epithelial barrier function: some new players and mechanisms. Am J Physiol Lung Cell Mol Physiol. 2015;308: L731-L45.

14. Puchelle E, Zahm JM, Tournier JM, Coraux C. Airway epithelial repair, regeneration, and remodeling after injury in chronic obstructive pulmonary disease. Proc Am Thorac Soc. 2006;3:726-33.

15. Hallstrand TS, Hackett TL, Altemeier WA, et al. Airway epithelial regulation of pulmonary immune homeostasis and inflammation. Clin Immunol. 2014;151:1-15.

16. Eapen MS, Hansbro PM, McAlinden K, et al. Abnormal M1/M2 macrophage phenotype profiles in the small airway wall and lumen in smokers and chronic obstructive pulmonary disease (COPD). Sci Rep. 2017;7:13392. 
17. Eapen MS, McAlinden K, Tan D, et al. Profiling cellular and inflammatory changes in the airway wall of mild to moderate COPD. Respirology. 2017;22:1125-32.

18. Peters EJ, Morice R, Benner SE, et al. Squamous metaplasia of the bronchial mucosa and its relationship to smoking. Chest. 1993;103:1429-32.

19. Crystal RG. Airway basal cells. The "smoking gun" of chronic obstructive pulmonary disease. Am J Respir Crit Care Med. 2014;190:1355-62.

20. Eapen MS, Myers S, Lu W, et al. sE-cadherin and sVE-cadherin indicate active epithelial/endothelial to mesenchymal transition (EMT and EndoMT) in smokers and COPD: implications for new biomarkers and therapeutics. Biomarkers 2018;23:709-711.

21. Sohal SS. Airway basal cell reprogramming and EMT: potential key to understanding early COPD. Am J Respir Crit Care Med 2018;197:1644-1645.

22. Sohal SS. Epithelial and endothelial cell plasticity in chronic obstructive pulmonary disease (COPD). Respir Investig. 2017;55:104-13.

23. Sohal SS, Walters EH. Epithelial mesenchymal transition (EMT) in small airways of COPD patients. Thorax. 2013;68:783-4.

24. Sohal SS. Chronic obstructive pulmonary disease (COPD) and lung cancer: epithelial mesenchymal transition (EMT), the missing link? EBioMedicine. 2015;2:1578-9.

25. Kumar JM, Chris W, Suji EM, et al. Epithelial-mesenchymal transition, a spectrum of states: role in lung development, homeostasis, and disease. Dev Dyn. 2018;247:346-58.

26. Königshoff M. Lung cancer in pulmonary fibrosis: tales of epithelial cell plasticity. Respiration. 2011;81:353-8.

27. Sohal SS, Walters EH. Advanced non-small-cell lung cancer. N Engl J Med. 2017;377:1998-9.

28. Nowrin K, Sohal SS, Peterson G, Patel R, Walters EH. Epithelialmesenchymal transition as a fundamental underlying pathogenic process in COPD airways: fibrosis, remodeling and cancer. Expert Rev Respir Med. 2014;8:547-59.

29. Mahmood MQ, Sohal SS, Shukla SD, et al. Epithelial mesenchymal transition in smokers: large versus small airways and relation to airflow obstruction. Int $\mathrm{J}$ Chron Obstruct Pulmon Dis. 2015;10:1515-24.

30. Schneider M, Hansen JL, Sheikh SP. S100A4: a common mediator of epithelial-mesenchymal transition, fibrosis and regeneration in diseases? J Mol Med. 2008;86:507-22.

31. Sohal S, Reid D, Soltani A, et al. Reticular basement membrane fragmentation and potential epithelial mesenchymal transition is exaggerated in the airways of smokers with chronic obstructive pulmonary disease. Respirology. 2010;15:930-8.

32. Soltani A, Reid DW, Sohal SS, et al. Basement membrane and vascular remodelling in smokers and chronic obstructive pulmonary disease: a cross-sectional study. Respir Res. 2010;11:105.

33. Sohal SS, Reid D, Soltani A, et al. Evaluation of epithelial mesenchymal transition in patients with chronic obstructive pulmonary disease. Respir Res. 2011;12:130.

34. Wang Q, Wang Y, Zhang Y, Zhang Y, Xiao W. The role of uPAR in epithelial-mesenchymal transition in small airway epithelium of patients with chronic obstructive pulmonary disease. Respir Res. 2013;14:67.

35. Ng Kee Kwong F, Nicholson AG, Harrison CL, et al. Is mitochondrial dysfunction a driving mechanism linking COPD to nonsmall cell lung carcinoma? Eur Respir Rev 2017;26.

36. Milara J, Peiró T, Serrano A, Cortijo J. Epithelial to mesenchymal transition is increased in patients with COPD and induced by cigarette smoke. Thorax. 2013;68:410-20.

37. Milara J, Peiro T, Serrano A, et al. Roflumilast N-oxide inhibits bronchial epithelial to mesenchymal transition induced by cigarette smoke in smokers with COPD. Pulm Pharmacol Ther. 2014;28:138-48.
38. Gohy ST, Hupin C, Fregimilicka C, et al. Imprinting of the COPD airway epithelium for dedifferentiation and mesenchymal transition. Eur Respir J. 2015;45:1258-72.

39. Sohal SS, Eapen MS, Ward C, Walters EH. Epithelial Mesenchymal Transition (EMT): a necessary new therapeutic target in COPD? Am J Respir Crit Care Med 2017;196:393-394.

40. Sohal SS, Hansbro PM, Walters EH. Epithelial mesenchymal transition in chronic obstructive pulmonary disease, a precursor for epithelial cancers: understanding and translation to early therapy. Ann Am Thorac Soc. 2017;14:1491-2.

41. Sohal SS, Walters EH. Essential need for rethink of COPD airway pathology: implications for new drug approaches for prevention of lung cancer as well as small airway fibrosis. Int J Chron Obstruct Pulmon Dis. 2017;12:2677-9.

42. Soltani A, Walters EH, Reid DW, et al. Inhaled corticosteroid normalizes some but not all airway vascular remodeling in COPD. Int J Chron Obstruct Pulmon Dis. 2016;11:2359-67.

43. Sohal SS. Endothelial to mesenchymal transition (EndMT): an active process in chronic obstructive pulmonary disease (COPD)? Respir Res. 2016;17:20.

44. Parimon $\mathrm{T}$, Chien J, Bryson $\mathrm{C}$, et al. Inhaled corticosteroids and risk of lung cancer among patients with chronic obstructive pulmonary disease. Am J Respir Crit Care Med. 2007;175: 712-9.

45. Sohal SS. Fluticasone propionate and increased risk of pneumonia in COPD: is it PAFR-dependent? Int J Chron Obstruct Pulmon Dis. 2017;12:3425-7.

46. Eapen MS, Sharma P, Moodley YP, Hansbro PM, Sohal SS. Dysfunctional Immunity and Microbial Adhesion Molecules in Smoking-Induced Pneumonia. Am J Respir Crit Care Med. 2018 Oct 5. https://doi.org/10.1164/rccm.201808-1553LE. [Epub ahead of print].

47. Shukla SD, Sohal SS, Mahmood MQ, et al. Airway epithelial platelet-activating factor receptor expression is markedly upregulated in chronic obstructive pulmonary disease. Int $\mathrm{J}$ Chron Obstruct Pulmon Dis. 2014;9:853-61.

48. Eapen MS, Hansbro PM, Larsson-Callerfelt AK, Jolly MK, Myers S, Sharma P, Jones B, Rahman MA, Markos J, Chia C, Larby J, Haug G, Hardikar A, Weber HC, Mabeza G, Cavalheri V, Khor YH, McDonald CF, Sohal SS. Chronic Obstructive Pulmonary Disease and Lung Cancer: Underlying Pathophysiology and New Therapeutic Modalities. Drugs. 2018 Nov 3. https://doi.org/10. 1007/s40265-018-1001-8. [Epub ahead of print].

49. Liu T-C, Jin X, Wang Y, Wang K. Role of epidermal growth factor receptor in lung cancer and targeted therapies. Am J Cancer Res. 2017;7:187-202.

50. Bethune G, Bethune D, Ridgway N, Xu Z. Epidermal growth factor receptor (EGFR) in lung cancer: an overview and update. $\mathrm{J}$ Thorac Dis. 2010;2:48-51.

51. Shaykhiev R, Crystal RG. Early events in the pathogenesis of chronic obstructive pulmonary disease. smoking-induced reprogramming of airway epithelial basal progenitor cells. Ann Am Thorac Soc. 2014;11:S252-S8.

52. Shaykhiev R, Zuo W-L, Chao I, et al. EGF shifts human airway basal cell fate toward a smoking-associated airway epithelial phenotype. Proc Natl Acad Sci USA. 2013;110:12102-7.

53. Kedzierski L, Tate MD, Hsu AC, et al. Suppressor of cytokine signaling (SOCS)5 ameliorates influenza infection via inhibition of EGFR signaling. Elife 2017;6.

54. Minor DM, Proud D. Role of human rhinovirus in triggering human airway epithelial-mesenchymal transition. Respir Res. 2017;18:110.

55. Mahmood MQ, Ward C, Muller HK, Sohal SS, Walters EH. Epithelial mesenchymal transition (EMT) and non-small cell lung cancer (NSCLC): a mutual association with airway disease. Med Oncol. 2017;34:45. 
56. Shigeki H, Hidehiko I, Chie M, et al. Membrane-anchored growth factors, the epidermal growth factor family: Beyond receptor ligands. Cancer Sci. 2008;99:214-20.

57. Schneider Marlon R, Wolf E. The epidermal growth factor receptor ligands at a glance. J Cell Physiol. 2008;218:460-6.

58. Li L, Qi L, Liang Z, et al. Transforming growth factor- $\beta 1$ induces EMT by the transactivation of epidermal growth factor signaling through HA/CD44 in lung and breast cancer cells. Int J Mol Med. 2015;36:113-22.

59. Daub H, Ulrich Weiss F, Wallasch C, Ullrich A. Role of transactivation of the EGF receptor in signalling by G-protein-coupled receptors. Nature. 1996;379:557.

60. Uchiyama-Tanaka Y, Matsubara H, Mori Y, et al. Involvement of HB-EGF and EGF receptor $<$ em $>$ trans $</$ em $>$ activation in TGF$\beta-$ mediated fibronectin expression in mesangial cells. Kidney Int. 2002;62:799-808.

61. Lo H-W, Hsu S-C, Xia W, et al. Epidermal growth factor receptor cooperates with signal transducer and activator of transcription 3 to induce epithelial-mesenchymal transition in cancer cells via upregulation of $<$ em $>$ TWIST $</$ em $>$ gene expression. Cancer Res. 2007;67:9066-76.

62. Stoll SW, Rittié L, Johnson JL, Elder JT. Heparin-binding EGFlike growth factor promotes epithelial-mesenchymal transition in human keratinocytes. J Invest Dermatol. 2012;132:2148-57.

63. Lai $\mathrm{T}$, Li Y, Chen M, et al. Heparin-binding epidermal growth factor contributes to COPD disease severity by modulating airway fibrosis and pulmonary epithelial-mesenchymal transition. Lab Investig. 2018;98:1159-69.

64. Mahmood MQ, Reid D, Ward C, et al. Transforming growth factor (TGF) beta1 and Smad signalling pathways: a likely key to EMT-associated COPD pathogenesis. Respirology. 2017;22:133-40

65. Springer J, Scholz FR, Peiser C, Groneberg DA, Fischer A. SMAD-signaling in chronic obstructive pulmonary disease: transcriptional down-regulation of inhibitory SMAD 6 and 7 by cigarette smoke. Biol Chem. 2004;385:649-53.

66. Uttamsingh S, Bao X, Nguyen KT, et al. Synergistic effect between EGF and TGF-beta1 in inducing oncogenic properties of intestinal epithelial cells. Oncogene. 2008;27:2626-34.

67. Baarsma HA, Königshoff M. 'WNT-er is coming': WNT signalling in chronic lung diseases. Thorax. 2017;72:746-59.

68. Zou W, Zou Y, Zhao Z, Li B, Ran P. Nicotine-induced epithelialmesenchymal transition via Wnt/beta-catenin signaling in human airway epithelial cells. Am J Physiol Lung Cell Mol Physiol. 2013;304:L199-209.

69. Baarsma HA, Spanjer AIR, Haitsma G, et al. Activation of WNT/ $\beta$-catenin signaling in pulmonary fibroblasts by TGF- $\beta 1$ is increased in chronic obstructive pulmonary disease. PLoS One. 2011;6:e25450.

70. DiRenzo DM, Chaudhary MA, Shi X, et al. A crosstalk between TGF- $\beta / S \operatorname{mad} 3$ and $\mathrm{Wnt} / \beta$-catenin pathways promotes vascular smooth muscle cell proliferation. Cell Signal. 2016;28:498-505.

71. Mahmood MQ, Walters EH, Shukla SD, et al. $\beta$-catenin, Twist and Snail: transcriptional regulation of EMT in smokers and COPD, and relation to airflow obstruction. Sci Rep. 2017;7:10832.

72. Talele Nilesh P, Fradette J, Davies John E, Kapus A, Hinz B. Expression of $\alpha$-smooth muscle actin determines the fate of mesenchymal stromal cells. Stem Cell Rep. 2015;4:1016-30.

73. Löfdahl M, Kaarteenaho R, Lappi-Blanco E, Tornling G, Sköld MC. Tenascin-C and alpha-smooth muscle actin positive cells are increased in the large airways in patients with COPD. Respir Res. 2011;12:48.

74. Karvonen HM, Lehtonen ST, Harju T, et al. Myofibroblast expression in airways and alveoli is affected by smoking and COPD. Respir Res. 2013;14:84.
75. Hallgren O, Rolandsson S, Andersson-Sjöland A, et al. Enhanced ROCK1 dependent contractility in fibroblast from chronic obstructive pulmonary disease patients. J Transl Med. 2012;10:171.

76. Hallgren O, Nihlberg K, Dahlbäck M, et al. Altered fibroblast proteoglycan production in COPD. Respir Res. 2010;11:55.

77. Larsson-Callerfelt A-K, Hallgren O, Andersson-Sjöland A, et al. Defective alterations in the collagen network to prostacyclin in COPD lung fibroblasts. Respir Res. 2013;14:21.

78. Harju T, Kinnula VL, Pääkkö P, et al. Variability in the precursor proteins of collagen I and III in different stages of COPD. Respir Res. 2010;11:165.

79. Liu G, Cooley MA, Jarnicki AG, et al. Fibulin-1 regulates the pathogenesis of tissue remodeling in respiratory diseases. JCI Insight 2016;1.

80. Hsu AC, Starkey MR, Hanish I, et al. Targeting PI3K-p110alpha suppresses influenza virus infection in chronic obstructive pulmonary disease. Am J Respir Crit Care Med. 2015;191: 1012-23.

81. Starkey MR, Jarnicki AG, Essilfie AT, et al. Murine models of infectious exacerbations of airway inflammation. Curr Opin Pharmacol. 2013;13:337-44.

82. Shukla SD, Fairbairn RL, Gell DA, et al. An antagonist of the platelet-activating factor receptor inhibits adherence of both nontypeable Haemophilus influenzae and Streptococcus pneumoniae to cultured human bronchial epithelial cells exposed to cigarette smoke. Int J Chron Obstruct Pulmon Dis. 2016;11: 1647-55.

83. Shukla SD, Mahmood MQ, Weston S, et al. The main rhinovirus respiratory tract adhesion site (ICAM-1) is upregulated in smokers and patients with chronic airflow limitation (CAL). Respir Res. 2017;18:6.

84. Shukla SD, Muller HK, Latham R, Sohal SS, Walters EH. Platelet-activating factor receptor (PAFr) is upregulated in small airways and alveoli of smokers and COPD patients. Respirology. 2016;21:504-10.

85. Shukla SD, Sohal SS, O'Toole RF, Eapen MS, Walters EH. Platelet activating factor receptor: gateway for bacterial chronic airway infection in chronic obstructive pulmonary disease and potential therapeutic target. Expert Rev Respir Med. 2015;9: 473-85.

86. Sohal SS, Eapen MS, Shukla SD, et al. Novel insights into chronic obstructive pulmonary disease (COPD): an overview. Eur Med J -Respir. 2014;2:81-7.

87. Sohal SS, Hansbro PM, Shukla SD, Eapen MS, Walters EH. Potential mechanisms of microbial pathogens in idiopathic interstitial lung disease. Chest. 2017;152:899-900.

88. Jones B, Donovan C, Liu G, et al. Animal models of COPD: what do they tell us? Respirology. 2017;22:21-32.

89. Sohal SS, Mahmood QM, Walters HE. Clinical significance of epithelial mesenchymal transition (EMT) in chronic obstructive pulmonary disease (COPD): potential target for prevention of airway fibrosis and lung cancer. Clin Transl Med. 2014; $3: 33$.

90. Sohal SS, Reid D, Soltani A, et al. Changes in airway histone deacetylase 2 in smokers and COPD with inhaled corticosteroids: a randomized controlled trial. PLoS One. 2013;8:e64833.

91. Sohal SS, Soltani A, Reid D, et al. A randomized controlled trial of inhaled corticosteroids (ICS) on markers of epithelialmesenchymal transition (EMT) in large airway samples in COPD: an exploratory proof of concept study. Int J Chron Obstruct Pulmon Dis. 2014;9:533-42.

92. Soltani A, Sohal SS, Reid D, et al. Vessel-associated transforming growth factor-beta1 (TGF-\&946 1) is increased in the bronchial reticular basement membrane in COPD and normal smokers. PLoS One. 2012;7:1-5. 
93. Simpson JL, Powell H, Baines KJ, et al. The effect of azithromycin in adults with stable neutrophilic COPD: a double blind randomised, placebo controlled trial. PLoS One. 2014;9:e105609.

94. Eapen MS, Kota A, Vindin H. et al. Apoptosis signal-regulating kinase 1 (ASK1) inhibition attenuates human airway smooth muscle growth and migration in chronic obstructive pulmonary disease (COPD). Clin Sci . 2018;132:1615-27.

95. Jaffar J, Unger S, Corte TJ, et al. Fibulin-1 predicts disease progression in patients with idiopathic pulmonary fibrosis. Chest. 2014;146:1055-63. 